\title{
Criblage de nouveaux gènes cibles des récepteurs nucléairesdes oxystérols LXRs impliqués dans le maintien de l'épithélium épididymaire et la maturation des spermatozoïdes dans l'épididyme
}

\author{
Ayhan KOCER, Fabrice SAEZ1, Kevin MOUZAT2, Patrick VERNET1, \\ Jean-Marc A. LOBACCARO2, JoëI R. DREVET1 \\ Laboratoire de Biologie du Développement et de la Reproduction ; INRA, Jouy en Josas, \\ 1Epididyme et Maturation des Gamètes Mâles ; UMR CNRS 6547-GEEM - Université Blaise Pascal, Aubière, \\ 2 Physiologie Comparée et Endocrinologie Moléculaire ; UMR CNRS 6547-GEEM - Université Blaise Pascal, \\ Aubière.
}

\section{RESUME}

Les récepteurs nucléaires des oxystérols LXRs sont impliqués dans l'homéostasie du cholestérol et le métabolisme lipidique. Les souris déficientes pour les 2 isoformes LXR $\alpha$ et LXR présentent une perturbation sévère de la structure de l'épithélium des segments 1 et 2 de la tête de l'épididyme ainsi qu'une fragilité des spermatozoïdes. Ces altérations ont pour conséquence d'engendrer une stérilité totale chez les souris mâles âgées de $\mathbf{1 0}$ mois.

A ce jour, aucun travail n'a été effectué sur le rôle des LXRs au niveau de l'épididyme. Une lignée cellulaire issue de la tête de l'épididyme murin (cellules B2) a été utilisée pour rechercher in vitro des gènes cibles épididymaires des LXRs. La présence d'une isoforme des LXRs (LXR $\alpha)$ a été mise en évidence par immunocytochimie et la capacité de réponse des cellules $B 2$ à un agoniste synthétique des LXRs (T0901317) a été vérifiée. Ces résultats valident les cellules $\mathrm{B} 2$ comme modèle d'étude. Des analyses protéomiques en électrophorèse bidimensionnelle ont été menées sur les cellules B2 traitées au T0901317. Cela a permis d'isoler 8 protéines régulées positivement par les LXRs. Une seule a pu être identifiée : la polyubiquitine, dont l'implication dans l'homéostasie cellulaire du cholestérol a déjà été rapportée.

Mots clés : épididyme, récepteurs nucléaires, $L X R$, cholestérol, reproduction

\section{INTRODUCTION}

\section{A. Epididyme}

\section{Anatomo-histologie}

Du préfixe grec épi (sur) et de la racine didyme (jumeau testicule), l'épididyme est un long canal, situé sur la face postérieure du testicule, qui relie les canaux efférents au canal déférent. Ce canal est très contourné et forme des lobules séparés par des travées conjonctives. Le canal épididymaire est de longueur variable selon les espèces (un mètre chez la souris, cinq mètres chez l'homme et quatre vingt mètres chez l'étalon) [6]. Cet organe peut être divisé chez les mammifères en trois régions anatomiquement distinctes : la tête (région proximale ou antérieure) qui intègre l'extrémité des canaux efférents et le segment initial, le corps (partie médiane) et la queue (région distale ou postérieure) d'apparence plus bulbeuse, connectée au canal déférent $[23,27]$. Chez la souris, la tête de l'épididyme peut être subdivisée, selon les auteurs, en 3 ou 5 régions, sur la base d'une séparation physique de sous territoires par l'intermédiaire de cloisons conjonctives ou septa [1] et/ou de caractéristiques structurales des cellules principales [2].

\section{Correspondance :}

Pr Joël DREVET - Epididyme et Maturation des Gamètes Mâles. UMR CNRS 6547 - GEEM Université Blaise Pascal 24 Avenue des Landais - 63177 Aubière. France Tel 0473407413 - Fax 0473407042 Email Joël.drevet@univ-bpclermont.fr 
D'un point de vue histologique, la lumière de l'épididyme est bordée d'un épithélium pseudostratifié chez la souris, constitué de plusieurs types cellulaires : une couche de cellules principales où s'intercalent des cellules apicales, claires et en halo $[57,54]$. Ces différents types de cellules présentent des caractéristiques structurales et fonctionnelles très variées. Le diamètre du canal épididymaire augmente de la tête vers la queue en raison de la diminution de la hauteur des cellules principales. La paroi du tubule est entourée de fibres musculaires lisses qui présentent des contractions péristaltiques régulières, contrôlées par des fibres nerveuses sympathiques contenues dans du tissu conjonctif [53].

\section{Fonctions de l'épididyme}

\section{a)Transport, maturation, protection et stockage des spermatozoïdes}

Après avoir traversé les canaux efférents, les spermatozoïdes sont pris en charge par l'épididyme qui assure leur transit par les contractions des fibres musculaires lisses qui l'entourent afin de les acheminer vers la queue de l'épididyme. C'est au cours de ce transit que se fait la maturation des spermatozoïdes. En effet, d'un point de vue fonctionnel, les spermatozoïdes qui sortent des testicules sont immobiles et incapables de reconnaître et de féconder l'ovocyte. La maturation post-testiculaire, permettant aux spermatozoïdes d'acquérir le pouvoir fécondant et la mobilité, se déroule progressivement durant la traversée de l'organe et plus ou moins précocement selon les espèces. Cela se fait grâce à une interaction perpétuelle, tout le long de l'épididyme, entre les spermatozoïdes immatures et le microenvironnement intraluminal créé par l'épithélium épididymaire. En effet, la composition du liquide intraluminal varie graduellement le long de l'épididyme de façon propre à chaque région de l'organe. Cela va ainsi créer un environnement unique dû, en partie, à la spécificité tissulaire, territoriale et cellulaire d'expression de gènes codant pour des protéines ubiquitaires ou spécifiques sécrétées ou relarguées par des processus apocrines [11, 34].

La composition du fluide résulte également de l'absorption de la majorité 'du liquide provenant des testicules via les canaux efférents dans un premier temps, puis au sein de l'épididyme du transport sélectif de composants provenant du sérum et de la sécrétion de macromolécules synthétisées par l'épithélium épididymaire, plus particulièrement par les cellules principales (de la tête). L'ensemble de ces phénomènes va entraîner des modifications morphologiques et biochimiques des spermatozoïdes telles que le remaniement de leur membrane plasmique. Ces remaniements sont surtout des modifications de la composition lipidique et protéique de la membrane plasmique des spermatozoïdes qui seront abordés plus loin dans ce même chapitre. Le fluide épididymaire va également participer à la survie des spermatozoïdes, par la présence de petites molécules organiques telles que le glucose, l'inositol ou la carnitine. Cette dernière est captée par les spermatozoïdes pour être transformée en acétyl carnitine qui sera utilisée comme un substrat énergétique pour la mobilité [9].
Le fluide épididymaire va aussi maintenir l'intégrité des spermatozoïdes. En effet, les spermatozoïdes sont des cellules haploïdes avec un ADN fortement condensé, incapables de synthétiser des protéines et possédant un cytoplasme réduit. C'est pourquoi leurs propres protections face aux différents types d'agression telles que les attaques immunitaires, oxydatives et protéolytiques sont limitées. Cette protection est alors assurée d'une part par la présence de la barrière hémato-épididymaire qui protège les spermatozoïdes contre le système immunitaire [49] et d'autre part par la sécrétion de protéines et de petites molécules protectrices par l'épithélium épididymaire.

Les spermatozoïdes, plus que toute autre cellule, sont très exposés aux radicaux libres présents dans l'environnement à cause de la présence d'acides gras poly insaturés (AGPI) au niveau de leur membrane plasmique. Cette exposition est accrue par leur temps de passage et de stockage dans l'épididyme. Les espèces réactives de l'oxygène sont capables d'affecter l'intégrité des spermatozoïdes soit en entraînant des dommages de l'ADN, soit en peroxydant les AGPIs de la membrane plasmique, d'où la nécessité d'une protection accrue au niveau de l'épididyme. Cette protection est assurée par la sécrétion de protéines telles que des glutathion peroxydases (GPXs) [64], des superoxyde dismutases (SOD) [48], la catalase [60] et la « clusterin " [15]. D'autres protéines comme la "Cystatin-related epididymal spermatogenic " (CRES) ont un rôle d'inhibiteur de protéase, protégeant les spermatozoïdes contre les dommages protéolytiques possibles en cas de libération prématurée des enzymes acrosomiales durant le transit épididymaire [10]. Cette protection est maintenue même au niveau de la queue de l'épididyme qui sert de lieu de stockage pour les spermatozoïdes matures et assure le maintien de leur intégrité avant l'éjaculation.

\section{b) Réorganisation de la membrane spermatique}

Le fluide épididymaire, riche en lipides et protéines, va assurer des modifications morphologiques et biochimiques des spermatozoïdes, telles que le remaniement structural de leur membrane plasmique qui est à la base de la reconnaissance et de la fusion spermatozoïde-ovocyte.

\section{- Remodelage de la composition protéique}

Les modifications des protéines membranaires du spermatozoïde ont surtout lieu dans la partie proximale de l'épididyme. Elles consistent en des variations du degré de glycosylation [62, 61], de phosphorylation [46], d'oxydation des protéines [55], ou encore d'hydrolyses par le biais d'enzymes sécrétées dans le fluide (glycosidases, glycosyltransférases, hydrolases, protéases) [26]. De plus, la fixation aux spermatozoïdes de nouvelles protéines sécrétées par l'épididyme est le deuxième volet de la maturation membranaire des spermatozoïdes. Cette sécrétion de protéines se fait majoritairement au niveau de la tête de l'épididyme. En effet, $60 \%$ des protéines synthétisées dans la région proximale de l'épididyme chez les rongeurs sont sécrétées dans la lumière [63]. Chez d'autres mammifères comme le cheval, le bélier et le verrat, $80 \%$ des protéines sont sécrétées dans la tête de l'organe et environ 15 pro- 
téines différentes représentent la majorité des sécrétions [14]. Certaines, comme la protéine DE synthétisée et sécrétée par le segment proximal, viennent s'associer fortement à la région dorsale de l'acrosome du spermatozoïde par des liaisons ioniques [8]. La protéine DE semble jouer un rôle dans la reconnaissance entre les spermatozoïdes et l'ovocyte. Cette action a été mise en évidence suite à l'observation que l'immunisation de rats mâles et fernelles par la protéine DE provoque une inhibition de la fertilité. D'autres protéines telles que la protéine P26h chez le hamster (orthologue de $\mathrm{P} 34 \mathrm{H}$ chez l'homme), synthétisée au niveau du corps de l'épididyme, viennent se fixer dans la membrane plasmique au niveau de la région acrosomique du spermatozoïde via une ancre lipidique $[22,39$, 40]. Cette protéine interviendrait dans la liaison des spermatozoïdes avec la zone pellucide des ovocytes. La plupart de ces protéines ont donc un rôle important dans l'acquisition du pouvoir fécondant.

A ce remodelage protéique s'ajoute un remodelage lipidique de la membrane plasmique du spermatozoïde.

\section{- Remodelage lipidique de la membrane plasmique}

La membrane cellulaire forme une barrière structurale plus ou moins perméable entre le cytoplasme et le compartiment extracellulaire. Elle forme également une matrice permettant l'incorporation de protéines. Elle est constituée d'un mélange hétérogène de phospholipides, de glycolipides, de stérols et de glycoprotéines [56]. La proportion relative de ces différents éléments varie au cours de leur maturation épididymaire, aboutissant à une membrane possédant des propriétés particulières [25]. En effet, de manière générale, chez de nombreuses espèces, on observe au cours de la maturation épididymaire une augmentation des AGPIs (acide docosapentaénoïque, acide docosahéxaénoïque) par rapport aux acides gras saturés (AGS) [24]. Dans le même temps, le rapport cholestérol/phospholipides (chol/PL) diminue entraînant une augmentation de la fluidité de la membrane plasmique du spermatozoïde. Le rapport chol/PL est à la fois un indicateur de la fluidité et un déterminant dans les phénomènes de capacitation et de réaction acrosomique. En effet, de nombreux auteurs ont montré que l'efflux du cholestérol joue un rôle important dans les phénomènes de capacitation des spermatozoïdes et dans la signalisation conduisant à la réaction acrosomique. L'efflux du cholestérol semble augmenter la fluidité et la perméabilité de la membrane plasmique du spermatozoïde permettant, entre autre, l'influx d'ions calciques qui vont déclencher l'activation de signaux de transduction conduisant à la capacitation [65]. La diminution du cholestérol membranaire engendre des changements de la structure de la membrane, lui donnant des capacités fusogéniques essentielles à la réaction acrosomique et à la fusion spermatozoïde-ovocyte. D'autre part, des récepteurs comme le récepteur au mannose sont démasqués suite à cet efflux. Ce récepteur est impliqué dans l'interaction entre le spermatozoïde et la zone pellucide de l'ovocyte qui contient des résidus mannose et des protéines mannosylées. L'efflux du cholestérol induit également une augmentation du $\mathrm{pH}$ intracellulaire qui est requise pour la réaction acrosomique [13]. Tous ces événements indiquent un rôle central du cholestérol dans la physiologie et dans la maturation post testiculaire des spermatozoïdes.

\section{Contrôle de l'expression des gènes épididymaires}

L'expression région-spécifique des gènes épididymaires, accompagnant la segmentation fonctionnelle dans le sens antéropostérieur, sous-entend une régulation complexe et rigoureuse, reposant sur plusieurs niveaux.

Le premier niveau de régulation se fait via des facteurs provenant du fluide testiculaire. Cette régulation dite " lumicrine " a été mise en évidence après ligation des canaux efférents [31]. Son action porte principalement sur les cellules des segments initiaux et proximaux de la tête de l'épididyme. Les facteurs lumicrines, provenant majoritairement des testicules, peuvent être des composants solubles tels que des ions, des solutés organiques, des protéines et les androgènes associés aux « Sex Binding Proteins " (SBP) [43]. Parmi ces facteurs, on a identifié le " beta fibroblast growth factor » (bFGF) qui régule l'activité catalytique et le niveau d'expression de la $y$ glutamyl transpeptidase dans le segment initial de la tête de l'épididyme [36].

Le deuxième niveau de contrôle est réalisé par des facteurs dits paracrines. En effet, les activités de sécrétion d'une région de l'épididyme peuvent influencer ou réguler d'autres régions épididymaires. Cela a été mis en évidence dans le modèle de souris invalidées pour le récepteur tyrosine kinase "c-ros » dont le phénotype est une absence de différenciation du segment initial de l'épididyme. Dans ce contexte, on enregistre des changements dans les profils d'expression génique et protéique des régions sousjacentes [12]. Parmi ces facteurs paracrines, on trouve aussi la proenképhaline sécrétée par le segment initial de la tête de l'épididyme [21], ou les lipocalines comme l'" epididymal retinoic acid binding protein » (E-RABP) [38] sécrétée au niveau de la tête et du corps de l'épididyme. Cette dernière protéine semble être impliquée dans la régulation paracrine de l'expression de gènes en contrôlant la voie de signalisation de l'acide rétinoïque.

Enfin, à toutes ces régulations s'ajoute une régulation endocrine. Le mécanisme par lequel les systèmes endocriniens participent à l'expression des gènes épididymaires de manière région spécifique peut être dû à une distribution restreinte des récepteurs et/ou des ligands [12]. II est bien établi que la différenciation et les fonctions épididymaires sont principalement sous le contrôle des androgènes tels que la testostérone dont la forme la plus active est la dihydrotestostérone (DHT) issue de la conversion de la testostérone via l'enzyme 5 a réductase présente au niveau des cellules épididymaires [53]. Ces composés agissent via un récepteur nucléaire spécifique "Androgen Receptor " (AR). Une fois le complexe récepteur/ligand formé, celui-ci se fixe sur des séquences nucléiques spécifiques "Androgen Response Element " (ARE) situées sur les promoteurs des gènes cibles. Des expériences d'orchidectomie ont montré que les androgènes régulent l'expression de nombreux gènes codant pour des protéines consi- 
dérées comme des produits finaux de la différenciation cellulaire épithéliale tels que GPX5 et PEA3 $[16,37,44,17]$. D'autres systèmes endocriniens peuvent contrôler l'expression régionalisée des gènes de l'épididyme. Ceci a pu être observé après l'invalidation de gènes tels que le gène codant pour le récepteur aux œstrogènes « Estrogen Receptor " (ER). Ce récepteur est principalement exprimé au niveau des canaux efférents et du segment 1 de la tête de l'épididyme et semble réguler la réabsorption du fluide luminal, le transport ionique et le maintien de la structure épithéliale $[18,29,30]$. Les souris mâles ERa $\%$ sont stériles, en partie suite à un défaut de réabsorption du fluide testiculaire par les canaux efférents.

De la même façon, il a été montré que l'acide rétinoïque peut participer à la modulation de l'expression régionalisée des gènes épididymaires notamment à cause de la différence de distribution spatiale des récepteurs à l'acide rétinoïque " Retinoid Acid Receptor » (RAR) et " Retinoid X Receptor " (RXR) $[68,3]$. Plus récemment, l'invalidation des gènes codant pour les récepteurs nucléaires " Liver $X$ Receptor $\alpha$ et $\beta$ » (LXR $\alpha$ et LXRß) impliqués dans l'homéostasie du cholestérol et le métabolisme lipidique, suggère aussi que les LXRs seraient impliqués dans le maintien de la structure de l'épithélium de l'épididyme au niveau des segments 1 et 2 de la tête [19].

\section{B. Les Récepteurs Nucléaires LXRs}

L'accès privilégié aux modèles de souris invalidées pour les LXRs (collaboration : Pr J.M Lobacarro, UMR 6547 GEEM) associé à l'observation d'un phénotype épididymaire dans les doubles mutants LXR $\alpha \beta \%_{-}$, nous a conduit à nous intéresser aux rôles joués par ces récepteurs nucléaires aux oxystérols dans la physiologie de l'épididyme.

Les récepteurs LXRs codent pour des facteurs de transcription qui appartiennent à la superfamille des récepteurs nucléaires. II existe deux isoformes $L X R a$ ou NH1R3 [5] et LXRß ou NH1R2 [58]. L'analyse des séquences ADN a montré que ces deux récepteurs présentent une identité de $77 \%$ dans les domaines de liaison du ligand (LBD) et de liaison à I'ADN (DBD). Les profils d'expression des deux récepteurs sont différents : LXR $\alpha$ est préférentiellement exprimé dans les tissus où le métabolisme lipidique joue un rôle important (foie, rein, tissu adipeux...) alors que LXRß semble s'exprimer de façon plus ubiquiste $[41,42]$. Ces récepteurs agissent en formant des hétérodimères obligatoires avec le RXR qui est le récepteur de l'acide 9cis-rétinoïque. L'hétérodimère est permissif car il peut être activé à la fois par les ligands de LXR et/ou de RXR. L'hétérodimère $L X R / R X R$ se lie à des éléments de réponse "Liver X Response Element " (LXRE) de type " Direct Repeat " (DR4), c'est à dire une séquence hexanucléotidique imparfaite répétée et séparée de quatre nucléotides (la séquence canonique du DR4 est la suivante: TGGTCAnnnnAGTTCA). Les ligands naturels activant les LXRs sont des oxystérols qui sont des dérivés métaboliques du cholestérol [20,33]. Les agonistes synthétiques ont été développés pour les LXRs et les RXRs tels que le T0901317 [52] et le LG 268, respectivement [66].

\section{Rôles des LXRs}

Les LXRs jouent un rôle décisif dans l'homéostasie du cholestérol et le métabolisme lipidique. Ceci a été mis en évidence par la création par recombinaison homologue d'un modèle murin invalidé pour le gène $\operatorname{LXR} \alpha\left(L X R \alpha \%_{-}\right)$[48]. Ces souris ne sont plus capables de maintenir leur résistance naturelle à un régime riche en cholestérol ce qui se traduit par une accumulation très importante d'esters de cholestérol au niveau du foie [47]. De la même façon, des souris invalidées pour le gène LXRß (LXRß $\left.\%_{-}\right)$ont été obtenues mais ne présentent pas le même phénotype que les souris $L X R \alpha \%$. Les souris LXRß $\%$ présentent une résistance au cholestérol associée à une augmentation légère du poids corporel. Le croisement des deux lignées a permis de générer des souris présentant la double invalidation, ayant le même phénotype que les animaux LX $R \alpha \%$. Ces expériences d'invalidation attestent de l'implication importante du récepteur $L X R \alpha$ dans la régulation du métabolisme lipidique. Plusieurs gènes impliqués dans le transport, le stockage, la synthèse et le catabolisme du cholestérol dans les cellules hépatiques ont été identifiés comme étant des gènes cibles directs des LXRs.

\section{LXRs et le tractus génital mâle}

De nombreuses études ont pu mettre en évidence l'importance des lipides dans la physiologie du testicule, notamment dans sa fonction stéroïdogène. Par exemple, l'invalidation du gène de la lipase hormono-sensible (HSL) induit une stérilité. Cette enzyme hydrolyse les esters de cholestérol et libère le précurseur de la synthèse des stéroïdes : le cholestérol. Le rôle majeur du cholestérol au niveau des testicules et de l'épididyme a aussi été montré par des modèles "Knock out " des LXRs. Chez les souris $L X R \alpha \beta \%$, les analyses histologiques montrent une déstructuration massive du testicule survenant à 10 mois, qui se traduit par une hyperplasie des cellules de Leydig et une vacuolisation des cellules de Sertoli et une perturbation de la spermatogenèse $[66,35]$. Au niveau des segments 1 et 2 de la tête de l'épididyme, le phénotype se caractérise par une diminution de l'épaisseur des canaux et une absence des stéréocils de l'épithélium, généralement observés au niveau des cellules principales du segment 2 . Ce phénotype épididymaire apparaît seulement autour de 6 mois. Les spermatozoïdes de ces souris présentent des anomalies qui se traduisent par une fragilité de la pièce intermédiaire et une variation de l'angulation entre la tête et le flagelle. Les souris deviennent totalement stériles au bout de 10 mois $[19,67]$.

Ce phénotype observé au niveau de l'épididyme, chez les souris invalidées pour les LXRs, laisse supposer un rôle possible des LXRs dans la régulation de l'expression de gènes exprimés au niveau du segment 1 et 2 de la tête de l'épididyme, ainsi que dans le maintien de la structure de l'épithélium épididymaire et de l'intégrité des spermatozoïdes.

A ce jour, aucun travail n'a été effectué sur le rôle joué par les LXRs au niveau de l'épididyme. C'est pourquoi nous nous sommes intéressés à rechercher au niveau de l'épidi- 
dyme les gènes cibles des LXRs par une approche in vitro à partir d'une lignée cellulaire immortalisée, issue de la tête de l'épididyme murin (cellules B2). Ces cellules B2 ont été obtenues à partir de cultures primaires de cellules de la tête de l'épididyme dans lesquelles des mutations aléatoires ont conduit à leur immortalisation [7]. Ces cellules expriment plusieurs gènes considérés comme des marqueurs de l'activité de la tête de l'épididyme in vivo confirmant ainsi un état différencié proche de celui retrouvé dans l'organe.

Notre travail a tout d'abord consisté à valider notre modèle d'études en vérifiant qu'elles exprimaient les récepteurs LXRs et qu'elles répondaient bien aux agonistes. Puis, une études protéomique a été utilisée afin de rechercher des gènes cibles des LXRs.

\section{MATERIELS ET METHODES}

\section{Cultures cellulaires}

Deux lignées de cellules ont été utilisées pour notre étude. La lignée cellulaire NIH 3T3, issue de cellules fibroblastiques et la lignée cellulaire $B 2$ issue de culture primaire de la tête de l'épididyme de souris (obtenue au laboratoire par le Pr Lefrançois Martinez [7]).

Les cellules NIH 3T3 sont cultivées dans des boîtes de $10 \mathrm{~cm}$ de diamètre (Falcon, BD Biosciences, France) contenant $10 \mathrm{ml}$ de milieu de culture NIH 3 T3 (Tableau 1), à $37^{\circ} \mathrm{C}$, en présence de $5 \%$ de $\mathrm{CO}_{2}$. Les cellules $\mathrm{B} 2$ sont cocultivées avec les cellules NIH 3T3, qui servent de couche nourricière, à $35^{\circ} \mathrm{C}$ en présence de $5 \%$ de $\mathrm{CO}_{2}$ dans du milieu de prolifération B2 (Tableau 2). Cette co-culture se fait soit dans des boîtes de $10 \mathrm{~cm}$ de diamètre (Falcon) pour l'extraction des protéines, soit sur des lamelles de verre $18 \times 18 \mathrm{~mm}$, dans des boîtes 6 puits pour les analyses en immunocytochimie et de coloration à l'huile rouge.

Tableau 1 : composition du milieu de prolifération des cellules NIH 3 T3.

\begin{tabular}{ccc}
\hline Lignée & $\begin{array}{c}\text { Composition du } \\
\text { milieu de culture }\end{array}$ & Concentration \\
\hline L-glutamine & $2 \mathrm{mM}$ \\
Pénicilline & $100 \mathrm{U} / \mathrm{ml}$ \\
$\tilde{m}$ & $\begin{array}{c}\text { Streptomycine } \\
\text { Sérum de veau foetal } \\
\text { déstéroïdé }\end{array}$ & $100 \mu \mathrm{g} / \mathrm{ml}$ \\
& Milieu DMEM/HAM F12 & $10 \%(\mathrm{v} / \mathrm{v})$ \\
& qsp $500 \mathrm{ml}$
\end{tabular}

\section{Repiquage des cellules}

a) NIH 3 T3 : les cellules sont passées à confluence toutes les semaines, elles sont rincées 3 fois au PBS $1 X$ sans calcium ni magnésium (Invitrogen, Gibco, France), supplémenté par $100 \mathrm{U} / \mathrm{ml}$ de pénicilline et $50 \mu \mathrm{g} / \mathrm{ml}$ de strepto-
Tableau 2 : composition du milieu de prolifération des cellules B2.

\begin{tabular}{ccc}
\hline Lignée & $\begin{array}{c}\text { Composition du } \\
\text { milieu de culture }\end{array}$ & Concentration \\
\hline Transferrine & $10 \mu \mathrm{g} / \mathrm{ml}$ \\
Sélénium & $17,3 \mathrm{ng} / \mathrm{ml}$ \\
Insuline & $10 \mu \mathrm{g} / \mathrm{ml}$ \\
8 bromo AMPc & $25 \mu \mathrm{g} / \mathrm{ml}$ \\
L-glutamine & $2 \mathrm{mM}$ \\
Eิ & $10 \mathrm{ng} / \mathrm{ml}$ \\
& Ethanolamine & $0,6 \mu \mathrm{g} / \mathrm{ml}$ \\
Tampon HEPES & $20 \mathrm{mM}$ \\
Pénicilline & $100 \mathrm{U} / \mathrm{ml}$ \\
Streptomycine & $100 \mu \mathrm{g} / \mathrm{ml}$ \\
Toxine cholérique & $10 \mathrm{ng} / \mathrm{ml}$ \\
Hydrocortisone & $10-6 \mathrm{M}$ \\
Milieu DMEM/HAM F12 & qsp $500 \mathrm{ml}$
\end{tabular}

mycine. Puis, elles sont décollées par $1 \mathrm{ml}$ de solution de trypsine $0,4 \%(\mathrm{~m} / \mathrm{v})$-EDTA $1 \mathrm{mM}$ (Gibco) durant $20 \mathrm{~min}$ à $35^{\circ} \mathrm{C}$. Après neutralisation de la solution de trypsine par une dilution dans du milieu NIH 3T3, les cellules sont centrifugées pendant $5 \mathrm{~min}$ à $200 \mathrm{~g}$ à $4^{\circ} \mathrm{C}$. Ensuite, le culot est repris dans $5 \mathrm{ml}$ de milieu NIH $3 T 3$ et les cellules $3 T 3$ sont comptées sur une cellule de Mallasez avant d'être ensemencées à raison de 150000 cellules par boîte contenant du $10 \mathrm{ml}$ milieu NIH 3T3 (la viabilité des cellules est estimée par exclusion du bleu Trypan).

b) $B 2$ : on procède de la même façon sauf que les cellules sont décollées avec $2 \mathrm{ml}$ de solution de trypsine durant 20 min et qu'elles sont ensemencées sur des cellules 3T3 traitées à la mitomycine et incubées dans du milieu de prolifération.

\section{Immunocytochimie de LXR $\alpha$ dans les cellules B2}

\section{Immunodétection par fluorescence}

Après une semaine, les cellules cultivées sur lamelle de verre sont fixées dans les puits de culture avec de la paraformaldéhyde $4 \%(\mathrm{~m} / \mathrm{v}$ dans du PBS $1 \mathrm{X})$ durant $10 \mathrm{~min}$ à température ambiante et perméabilisées par un solution PBS 1X, Triton $1 \%$ durant $6 \mathrm{~min}$. Les cellules sont alors incubées dans une solution de saturation (PBS $1 \mathrm{X}$, sérum de chèvre $1 \%$ et BSA $8 \%$ ) durant une heure à température ambiante. Puis les cellules sont incubées avec l'anticorps anti-LXR $\alpha$ dilué au 150 ème dans une solution PBS $1 X$ contenant $1 \%$ de sérum de chèvre et $1 \%$ de BSA pendant toute la nuit à $4^{\circ} \mathrm{C}$. Après 3 rinçages de $5 \mathrm{~min}$ dans du PBS $1 \mathrm{X}$, les cellules sont incubées pendant une heure à température ambiante en présence d'anticorps secondaire antiIgG de lapin couplé à la fluorescéine dilué au 200 ème 
(PARIS, France) dans une solution de PBS $1 \mathrm{X}$ contenant $1 \%$ de sérum de chèvre et $1 \%$ de BSA. Enfin les cellules sont rincées avec du PBS $1 X$ et les lamelles sont montées sur des lames avec un milieu de montage colorant les noyaux au DAPI (Vectashield Hard set with DAPI, Vector).

\section{Huile Rouge}

Les cellules B2, cultivées sur des lamelles de verre, sont incubées pendant 48 heures avec $1 \mu \mathrm{M}$ d'un agoniste des LXRs (T0901317, Sigma, France) et/ou avec $1 \mu \mathrm{M}$ d'un agoniste des RXRs (LG 268, Ligand Pharmaceuticals, San Diego, CA). Les cellules sont alors fixées dans les puits de culture avec de la paraformaldéhyde $10 \%$ dans du PBS $1 \mathrm{X}$ (Sigma) durant 5 min à température ambiante et traitées avec le 1,2 propanediol (Sigma) pendant $1 \mathrm{~min}$ afin de chasser l'eau. Puis les lames sont plongées dans un bain d'huile rouge (Sigma) durant $30 \mathrm{~min}$ à $60^{\circ} \mathrm{C}$. Les cellules sont contre colorées avec l'hématoxyline Harris (Sigma) diluée au demi dans de l'eau distillé, durant $1 \mathrm{~min}$. Après rinçage à l'eau du robinet, les lamelles sont montées sur des lames avec du glycérol $50 \%$ et observées au microscope. Les inclusions lipidiques apparaissent en rouge.

\section{Electrophorèse bidimensionnelle}

\section{a) Extraction de protéines}

Les cellules B2, cultivées dans les boîtes $10 \mathrm{~cm}$, sont reprises puis centrifugées durant $10 \mathrm{~min}$ à $200 \mathrm{~g}$ à $4^{\circ} \mathrm{C}$. Les culots cellulaires sont repris avec un tampon de solubilisation des protéines (Tris $50 \mathrm{mM}$-EDTA $1 \mathrm{mM}$ ) ne contenant pas de sels pouvant gêner l'isofocalisation des protéines. L'extraction des protéines est alors réalisée par sonication ( $3 \times 30$ secondes) dans de la glace. L'homogénat est centrifugé à $10000 \mathrm{~g}$ durant $15 \mathrm{mn}$ à $4^{\circ} \mathrm{C}$, puis le surnageant est récupéré et les protéines totales sont dosées par la méthode colorimétrique de Bradford grâce au kit de dosage de protéine (BIO-RAD, France) en spectrophotométrie à $595 \mathrm{~nm}$. Le surnageant est stocké à $-20^{\circ} \mathrm{C}$.

\section{b) Isofocalisation (première dimension)}

\section{Réhydratation des bandelettes de gel}

La bandelette de gel d'isofocalisation $(7 \mathrm{~cm}, \mathrm{pH} 3-10$, BioRad) est réhydratée de manière passive avec du tampon de réhydratation (Urée $8 \mathrm{M}$, CHAPS $4 \%$, DTT $20 \mathrm{mM}$, Biolytes $0,2 \%$, bleu de bromophénol $0,001 \%$ ) contenant $100 \mu \mathrm{g}$ de protéines. La réhydratation dure huit heures à $20^{\circ} \mathrm{C}$, la bandelette étant recouverte d'huile minérale pour éviter le dessèchement du gel. Au cours de cette réhydratation, les protéines vont pénétrer dans le gel.

\section{Isofocalisation}

La focalisation est réalisée à l'aide de l'appareil « $\mathrm{PRO}$ TEAN IEF cell » (Bio-Rad). Les côtés acides et basiques du gel sont connectés respectivement à l'anode et à la cathode du plateau de focalisation et le gel est recouvert d'huile minérale pour éviter qu'il ne dessèche. Les paramètres de focalisation des protéines pour les bandelettes sont les suivants (1ère étape : 50 volts/9 heures, 2 ème étape : 200 volts/ 1 heure, 3 ème étape : 4000 volts/3 heures (rapi- de), 4ème étape : 4000 volts/heure (lent)). C'est durant l'isofocalisation que les protéines vont migrer selon leur point isoélectrique.

\section{c) SDS PAGE (deuxième dimension)}

\section{Equilibration}

Les protéines sont ionisées avec du SDS et réduites dans la solution d'équilibration I (Urée $6 \mathrm{M}$, SDS $2 \%$, Tris- $\mathrm{HCl}$ $0,375 \mathrm{M} \mathrm{pH} 8,8$, glycérol $20 \%$, DTT $130 \mathrm{mM}$ ) pendant $15 \mathrm{~min}$. Une seconde incubation est faite dans la solution d'équilibration II contenant du iodoacétamide, durant $20 \mathrm{mn}$ (Urée 6M. SDS $2 \%$, Tris-HCl 0,375 M pH 8,8, glycérol $20 \%$, iodoacétamide $135 \mathrm{mM}$ ). Ceci prévient la réoxydation des protéines au cours de l'électrophorèse et alkyle le DTT résiduel, minimisant ainsi les traînées verticales. Ces tampons doivent être préparés au dernier moment.

\section{SDS PAGE}

Les bandelettes sont déposées sur un gel SDS PAGE 12\% et recouvertes par un gel de concentration d'Agarose 1\% (Sea Plaque agarose, low geling temperature, TEBU, France). La migration est effectuée sous tension constante de $200 \mathrm{~V}$ et elle est stoppée lorsque le bleu de bromophénol sort du gel de séparation.

\section{Coloration au nitrate d'argent}

La coloration des polypeptides au nitrate d'argent ( $\mathrm{EMBL}$ silver staining protocol ») est celle décrite par Mortz et al [45]. Cette coloration est compatible avec le traitement des spots protéiques par spectrométrie de masse.

\section{Analyse des spots}

Les gels colorés sont scannés puis analysés par l'intermédiaire du logiciel PD QUEST version 7.1 (Bio-Rad). Les spots sélectionnés sont prélevés et envoyés pour être séquencés par spectrométrie de masse ("Matrix Assisted Laser Desorption Ionisation- Time Of Flight "MALDI-TOF ; voyager DE super STR Applied Biosystems, USA) à l'INRA de Theix (Christophe Chambon, plateforme protéomique Bloc 4). Les peptides sont analysés par le logiciel "Mascot " (http://www.matrixscience.com).

\section{RESULTATS}

\section{Localisation de la protéine $L X R$ dans les cellules $B 2$}

II a été montré par western blot que la protéine LXR s'exprime au niveau de la tête de l'épididyme in vivo [19]. II a été également montré par RT-PCR que les ARNm de LXR $\alpha$ et LXRß s'expriment dans les cellules B2 [7]. Aussi, nous nous sommes intéressés à visualiser par immunocytochimie la présence et la localisation de la protéine $L X R \alpha$ dans les cellules B2 à l'aide d'un anticorps anti-LXR $\alpha$ développé dans l'équipe du Pr. JM. Lobacarro.

L'analyse d'immunodétection en utilisant un anticorps secondaire marqué à la fluorescéine permet de montrer que $L X R \propto$ est présente au niveau péri nucléaire et nucléaire. Ceci est visible par la superposition de la fluorescence spécifique et du marquage du noyau au 
spécifique et du marquage du noyau au DAPI (Figure $1 \mathrm{~g}$ i). En revanche, les incubations avec l'anticorps secondaire marqué seul (Figure $1 \mathrm{~d}-\mathrm{f}$ ) ou avec le sérum pré immun (Figure $1 \mathrm{a}-\mathrm{c}$ ) ne montrent aucun signal fluorescent. Ces résultats attestent que le marquage est spécifique de la protéine $L X R \alpha$. La protéine $L X R \alpha$ est donc présente dans les cellules B2 et localisée au niveau nucléaire et péri nucléaire. Dans cette étude seule la protéine $L X R \alpha$ a été étudiée car nous ne possédions pas l'anticorps anti LXRß.

\section{Réponse des cellules B2 aux agonistes des LXRs et/ou des RXRs}

Dans le but d'utiliser les cellules B2 comme modèle dans la recherche de cibles épididymaires des LXRs nous avons testé si les cellules B2 étaient capables de répondre aux ligands synthétiques des LXRs (T0901317) et des RXRs (LG268). Pour visualiser la réponse physiologique des cellules B2 aux différents traitements, nous avons procédé à une coloration à l'huile rouge mettant spécifiquement en évidence les lipides neutres tels que les triglycérides et les esters de cholestérol.

Les résultats montrent qu'il y a une accumulation de gouttelettes lipidiques (marquées en rouge) au niveau cytoplasmique après traitement des cellules B2 au T0901317 seul (Figure 2b) par rapport aux cellules contrôles traitées avec le DMSO (Figure 2a). Cette accumulation cytoplasmique de gouttelettes lipidiques est observable sur la majorité des cellules B2. Les mêmes observations sont faites après traitement des cellules B2 au LG268 seul (Figure 2c). Le traitement avec les deux agonistes provoque une accumulation beaucoup plus importante des gouttelettes lipidiques (Figure 2d) par rapport à chacun des agonistes seul. L'association des deux ligands permet donc un effet synergique. L'ensemble de ces résultats confirme que les cellules $B 2$ répondent de manière très nette aux agonistes des LXRs.

Ces résultats suggèrent que ces cellules peuvent être utilisées comme modèle d'étude afin de rechercher des cibles épididymaires des LXRs in vitro.

\section{Etude du profil d'expression protéique des cellules B2}

Les cibles épididymaires des LXRs ont été recherchées in vitro sur les cellules B2 murines par une approche protéomique.

Les cellules ont été incubées durant $24,48,72$ heures $(h)$ avec $1 \mu \mathrm{M}$ d'agoniste des LXRs (T0901317). Après chaque temps d'incubation, les cellules ont été reprises afin d'extraire les protéines. Pour chacune des conditions, nous avons étudié le profil protéique des cellules B2 traitées ou non traitées avec le T0901317 par électrophorèse bidimensionnelle. Puis, l'ensemble des spots apparaissant pour chacune des conditions a pu être appréciè après coloration des gels SDS-PAGE au nitrate d'argent (Figure 3). L'observation de ces gels montre un profil de migration des protéines semblable pour chacune des conditions. On peut constater que peu de protéines sont détectées dans les régions de faible pl (entre 3 et 5). A l'inverse, beaucoup plus de protéines sont visibles à des pl élevés (entre 7 et 9 ). Afin d'analyser les gels de manière plus précise, nous avons procédé à une analyse informatique en utilisant le logiciel PD-QUEST (version 7.1 ; Bio-Rad). Après avoir défini un gel comme référence, le logiciel permet de comparer plusieurs gels d'une même condition entre eux (en l'occurrence quatre gels différents dans notre étude). Au moment de la comparaison, il est important de choisir un maximum de spots communs qui vont servir de repères. Ces repères vont permettre au logiciel d'établir une correspondance entre les gels moyens et de les normaliser en une géométrie cohérente et unique. Ainsi pour chacune des conditions, le logiciel va créer un gel de référence ou gel moyen représentatif des quatre gels différents en retenant seulement les spots communs. Les analyses comparatives sont ensuite réalisées à partir des gels moyens.

Dans un premier temps, nous avons comparé les gels moyens des conditions $24 \mathrm{~h}, 48 \mathrm{~h}, 72 \mathrm{~h}$ avec le gel moyen correspondant au contrôle DMSO. Dans un deuxième temps nous avons comparé les gels moyens $48 \mathrm{~h}$ et $72 \mathrm{~h}$ avec le gel moyen $24 \mathrm{~h}$. Ces deux étapes d'analyse successives nous ont permis d'identifier un certain nombre de spots identiques et non identiques à chaque condition. Les résultats obtenus sont indiqués dans le Tableau 3. Pour la suite de l'analyse, nous avons choisi de travailler sur des spots protéiques apparaissant de manière commune dans les trois conditions étudiées, et préférentiellement ceux dont l'intensité de coloration est nette. Les spots sélectionnés sont indiqués sur la Figure 3 : ils sont concentrés dans la zone de faible poids moléculaire (entre 13 et $25 \mathrm{kDa}$ ), avec des pl compris entre 5 et 8 environ (Figure $3 \mathrm{~b}, \mathrm{c}, \mathrm{d}$ ). Huit spots intéressants ont été identifiés sur les gels et prélevés pour être analysés en spectrométrie de masse MALDI-TOF. Avant d'être analysés par spectrométrie de masse, les spots subissent une digestion enzymatique à la trypsine afin de donner différents peptides. Les protéines correspondant aux peptides sont identifiées avec le programme "Mascot ». Une première série d'analyse en spectrométrie de masse n'a donné qu'un résultat significatif $(p<0,05)$ pour le spot 1 identifié comme étant la polyubiquitine 4 de souris « Mus musculus » (numéro d'accession AK088453, Genbank). En ce qui concerne les autres protéines, elles sont en cours d'analyse.

\section{DISCUSSION}

Les phénotypes observés chez les souris mutantes pour les deux gènes $L X R \alpha$ et $L X R ß$ suggèrent un rôle fonctionnel des LXRs au niveau de l'épididyme notamment dans le maintien de la structure de l'épithélium et l'intégrité des spermatozoïdes. Dans le but d'aborder le rôle des LXRs et des oxystérols dans la physiologie de l'épididyme, nous avons recherché in vitro les gènes qui sont des cibles directes ou indirectes des LXRs en utilisant des cellules épididymaires murines en culture [7].

Dans un premier temps, il était important de valider le modèle de cellules utilisées vis à vis de la réponse aux LXRs par différentes approches simples. Les expériences d'immunolocalisation montrent clairement que la protéine 

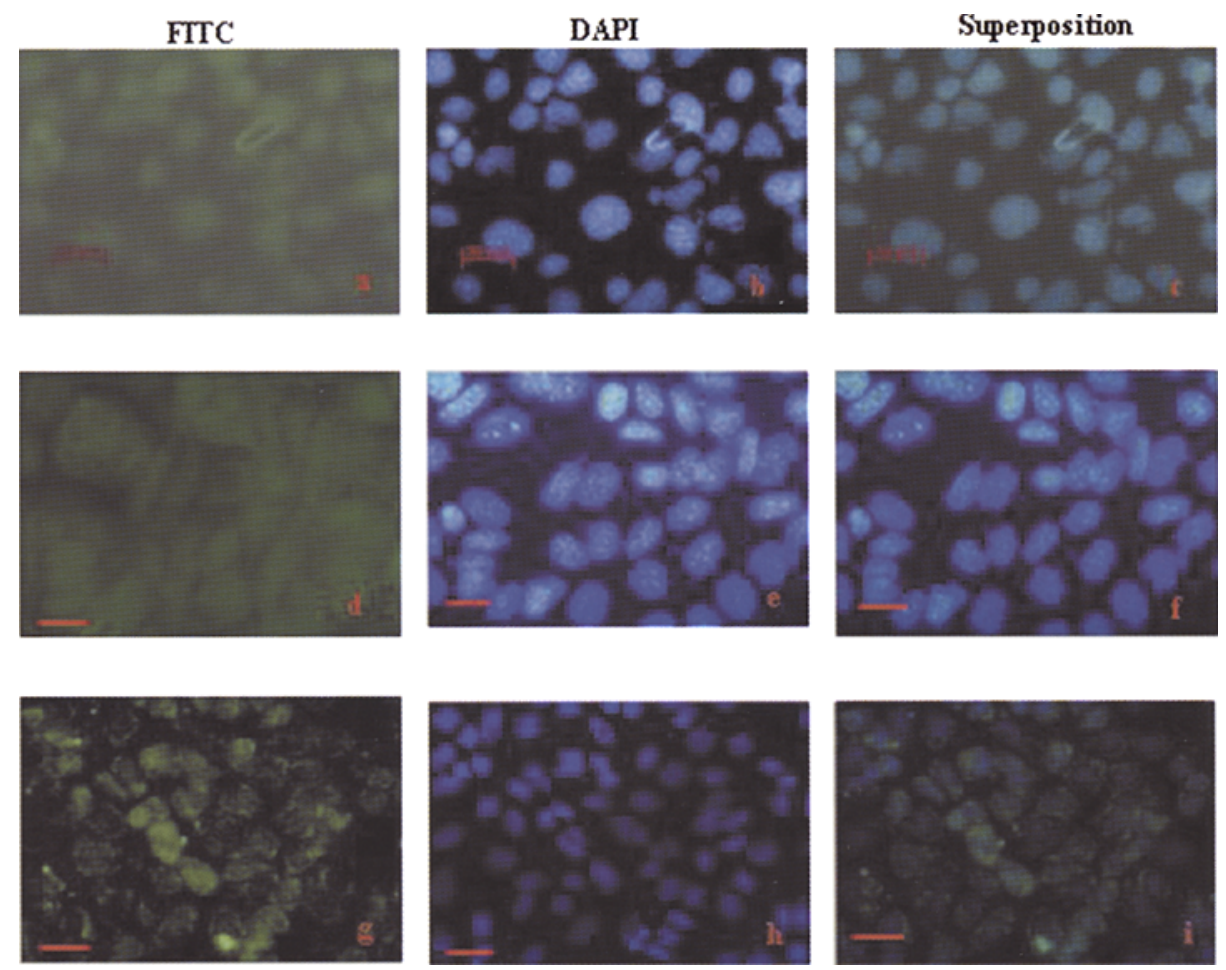

Figure 1 : Immunodétection par fluorescence de la protéine LXRa dans les cellules B2. Les cellules sont incubées soit en présence de sérum pré-immun (a-c), soit en présence de l'anticorps anti-LXR $\alpha(1 / 150 e)(9-i)$, puis en présence d'anticorps secondaire couplé à la fluorescéine (1/200e) donnant un marquage vert. Un témoin en présence d'anticorps secondaire seul été réalisé (d-f). Les noyaux sont colorés en bleu par le DAPI (b, e, h). Les images (c, $f$, i) correspondent à la superposition des deux images FITC et DAPI. Les barres de calibration représentent $50 \mu m$.

DMSO

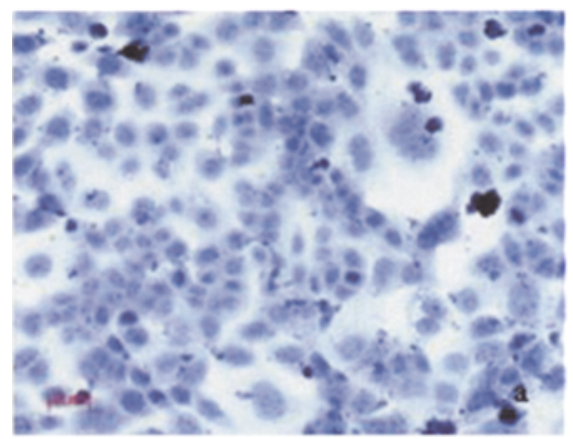

LG268

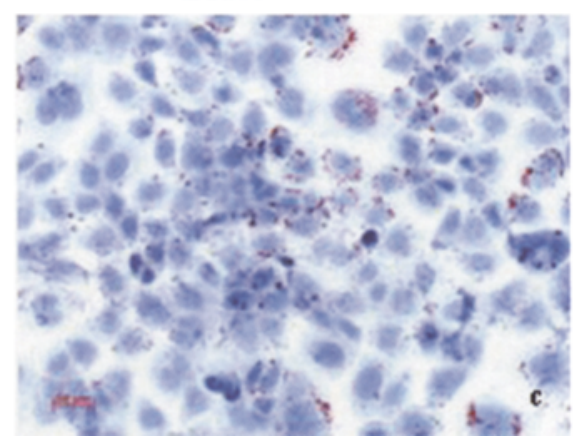

T0901317

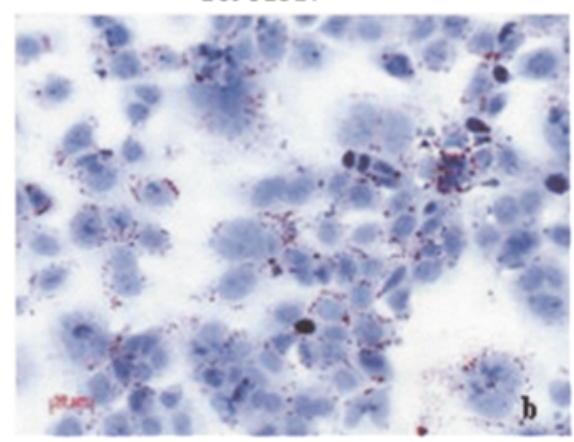

T0901317 + LG268

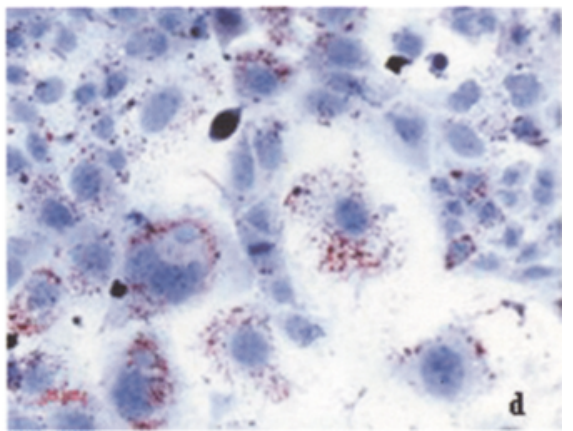

Figure 2 : Coloration à l'huile rouge des cellules B2 stimulées par les agonistes des LXRs et des RXRs. Les cellules sont incubées avec un agoniste synthétique des LXRs à $1 \mu M$ (T0901317) (b), avec un agoniste synthétique des RXRs à $1 \mu M$ (LG268) (c), ou avec les deux à la fois (d). Les cellules incubées avec le DMSO (a) correspondent au contrôle. Les cellules sont colorées à l'huile rouge après 48 heures d'incubation dans les différentes conditions, puis contre-colorées avec l'hématoxyline (coloration bleue). 

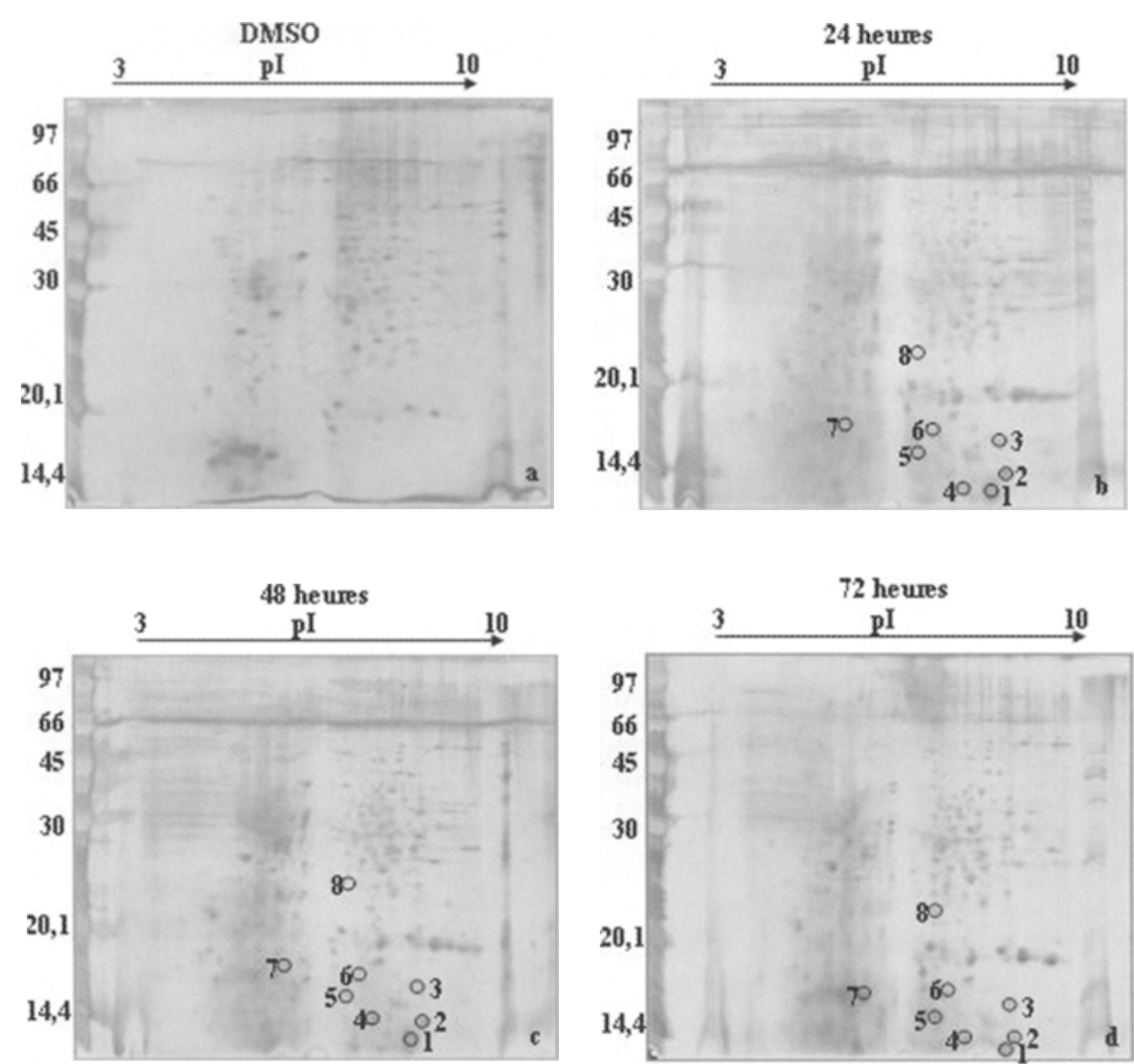

Figure 3 : Identification des spots suite à l'analyse des gels moyens. Les spots sélectionnés par l'analyse informatique des gels moyens sont repérés sur les gels d'électrophorèse bidimensionnelle (encerclés et numérotés). lls sont prélevés et analysés en spectrométrie de masse MALDl-TOF. Le poids moléculaire exprimé en kilo dalton (kDa) apparaît à gauche et le point isoélectrique (pl) en haut des gels.

Tableau 3 : Comparaison des spots des différents gels.

\begin{tabular}{lccccc}
\hline & DMSO/24H & DMSO/48H & DMSO/72H & 24/48H & 24/72H \\
\hline Spots Identiques & 225 & 226 & 223 & 247 & 979 \\
Spots non identiques & 119 & 152 & 128 & 94 \\
\hline
\end{tabular}

Les gels moyens 24,48 et 72 heures sont comparés avec le gel correspondant au DMSO. Puis les gels moyens 48 et 72 heures sont comparés avec le gel moyen correspondant à 24 heures. Les valeurs indiquent le nombre de spots identiques ou non identiques entre les deux conditions mentionnées.

LXR $\alpha$ est présente dans les cellules B2 et que sa distribution est nucléaire et péri nucléaire. Cette localisation n'est pas cohérente avec le dogme selon lequel les récepteurs nucléaires orphelins sont plutôt nucléaires et non cytoplasmiques. Cependant, certains auteurs ont pu observer de telles localisations cytoplasmiques pour d'autres récepteurs nucléaires tels que PPARg2 [59], RXRs et RARs (Nezzar H, communication personnelle). Sachant que la synthèse des protéines a lieu dans le cytoplasme, cela pourrait donc expliquer cette localisation péri nucléaire ou laisser supposer une action possible dans le cytoplasme. II serait intéressant d'étudier d'une part si cette localisation est retrouvée in vivo au niveau de l'épididyme par une approche d'immunohistochimie et d'autre part si cette loca- lisation péri nucléaire change pour une localisation nucléaire après traitement avec les agonistes des LXRs in vitro. Les mêmes expériences seront à réaliser lorsque l'anticorps anti-LXRß sera disponible.

Après avoir montré la localisation de LXR $\alpha$ dans nos cellules, il était important de déterminer la fonction de ces récepteurs dans ces cellules B2. C'est pourquoi nous avons entrepris de mettre en évidence cette fonction via une coloration à l'huile rouge. Les résultats de cette coloration montrent que les cellules B2 accumulent des gouttelettes lipidiques après incubation avec l'agoniste synthétique des LXRs (T0901317). De plus, comme attendu pour un hétérodimère $L X R / R X R$ permissif, cette accumulation est augmentée de manière synergique en incubant les cellules 
avec les deux agonistes des LXRs et des RXRs (T0901317 et LG268). Ces résultats ne permettent pas de discriminer l'action de $L X R \alpha$ par rapport à $L X R ß$ mais suggèrent l'existence d'un métabolisme lipidique actif dans les cellules B2. II serait intéressant de doser les lipides d'une part dans les cellules traitées ou non traitées avec l'agoniste des LXRs afin de connaître la nature des lipides accumulés (triglycérides, esters de cholestérol...), et d'autre part dans le milieu de culture sachant que les cellules B2 sont cultivées en absence de sérum.

Nous avons vu en introduction les remaniements importants du cholestérol de la membrane des spermatozoïdes au cours du transit épididymaire. Ces remaniements sont fondamentaux pour les capacités fonctionnelles des spermatozoïdes (capacitation, réaction acrosomique). La compréhension des mécanismes impliqués dans le mouvement du cholestérol dans les cellules $B 2$, en relation avec le rôle des LXRs, pourrait nous amener à mieux comprendre les phénomènes physiologiques in vivo. Ceci est supporté par les phénotypes observés sur les spermatozoïdes des souris déficientes pour les gènes de l'apolipoprotéine B (Apo B) [32] et du récepteur à l'apolipoprotéine E (ApoRE) [4] qui sont impliqués dans l'efflux cellulaire de cholestérol et exprimés dans l'épididyme. Ces souris sont stériles et présentent un défaut de maturation des spermatozoïdes pour lesquels on observe des aspects morphologiques anormaux, affectant notamment l'angulation flagellaire, phénotype retrouvé dans les animaux $L X R \alpha \beta \%$.

L'ensemble de ces résultats permet de considérer les cellules B2 comme un modèle in vitro opportun pour appréhender des gènes épididymaires cibles des LXRs. La recherche de gènes cibles a été menée par une approche protéomique. Cette méthode nous a permis d'identifier des protéines dont l'expression est régulée positivement par traitement avec l'agoniste des LXRs (T0901317) dans les trois conditions $(24 \mathrm{~h}, 48 \mathrm{~h}, 72 \mathrm{~h})$. Parmi huit spots sélectionnés, un seul (spot 1) a donné un résultat significatif après avoir été analysé par MALDI-TOF. Les autres spots n'ont pas pu être identifiés probablement car les protéines contenues étaient en trop faible quantité. Ces résultats s'expliquent en grande partie par les limites de la technique bidimensionnelle :

- La première limite repose sur le type de bandelettes utilisées. En effet, la quantité maximale de protéines séparées en première dimension est limitée à $100 \mu \mathrm{g}$ même si les recommandations du fournisseur indiquent jusqu'à $500 \mu g$. Lorsqu'on dépose de grandes quantités de protéines, les migrations (première et deuxième dimensions) ne se font pas correctement, probablement du à un trop fort encombrement. Pour s'affranchir de ces contraintes, il faudra utiliser des bandelettes de grande taille afin de pouvoir focaliser isoélectriquement de plus fortes quantités de protéines, et des bandelettes ayant des gammes de $\mathrm{pH}$ restreintes comprenant les pl des spots identifiés afin de mieux les séparer (pl de 5 à 10).

- La deuxième limite s'explique par le type de coloration utilisée. La coloration au nitrate d'argent est beaucoup plus sensible que celle utilisant le bleu de Coomassie colloïdal, permettant ainsi de visualiser des spots de faible intensité et donc de faible quantité alors que seules les protéines majeures sont révélées par le bleu de Coomassie colloïdal. De plus, avec le nitrate d'argent, la digestion à la trypsine ne s'effectue pas de façon optimale ce qui occasionne des erreurs dans l'analyse du séquençage. Dans nos conditions expérimentales, aucun spot n'a pu être visualisé en utilisant la méthode de coloration au bleu colloïdal, même pour des quantités de protéines élevées (150 et $200 \mu \mathrm{g}$ de protéines). Pour un séquençage efficace, il faudra grouper les spots d'au moins 4 à 6 gels différents afin d'avoir une quantité suffisante de protéines.

En ce qui concerne le spot identifié (spot 1), celui-ci correspond à une polyubiquitine. Ce résultat est intéressant car il a été décrit récemment que l'ubiquitine pouvait être impliqué dans plusieurs fonctions telles que la réparation de I'ADN, la transcription, la transduction de signaux et dans les phénomènes endocytose-exocytose [51]. De plus il a été montré qu'une régulation des stérols intracellulaires passe par une étape de protéolyse ubiquitine-dépendante de la " 3-hydroxy-3-methylglutaryl coenzyme A reductase " ou " HMG-CoA reductase " (HMGR) [50]. HMGR est une enzyme limitante de la synthèse endogène du cholestérol. Elle permet la transformation de l'acétate en mévalonate qui constitue la première étape limitante de la voie du mévalonate. C'est à partir du mévalonate que va se faire la synthèse endogène du cholestérol (Figure 4). Cette synthèse est régulée de manière très fine : selon la quantité de stérols présents dans la cellule, il va y avoir une régulation positive ou négative de la synthèse du cholestérol. La régulation fait intervenir un certain nombre d'acteurs, notamment les "Sterol Regulatory Element Binding Proteins " (SREBPs) qui régulent positivement HMGR. Ainsi l'excès de cholestérol ou de ses dérivés (oxystérols) va agir comme un inhibiteur de HMGR pré existant en induisant sa dégradation. Cette dégradation, qui se fait par le protéasome, est la résultante d'une polyubiquitination de HMGR induite par le cholestérol ou ses dérivés qui vont diminuer le taux de HMGR et donc la synthèse endogène du cholestérol [28]. Pour confirmer notre hypothèse, il faudra rechercher si l'expression de la protéine HMGR est diminuée après traitement des cellules B2 par le T0901317.

Pour la suite des travaux, de nouvelles analyses bidimensionnelles devraient permettre d'identifier tous les spots sélectionnés. Une fois les protéines identifiées, une analyse bibliographique sera menée pour vérifier si ces protéines sont des cibles connues des LXRs. Dans ce cas, il faudra étudier l'expression épididymaire de ces protéines, leur régionalisation éventuelle au niveau de la tête de l'épididyme plus précisément à l'endroit où apparaît le phénotype chez les souris $L X R \alpha \beta-$. par des analyses différentielles de l'expression in vivo (PCR quantitative en temps réel, northern blot). Si des anticorps sont disponibles, l'expression protéique et la localisation pourront être déterminées par des analyses immunohistochimiques. Si les protéines 


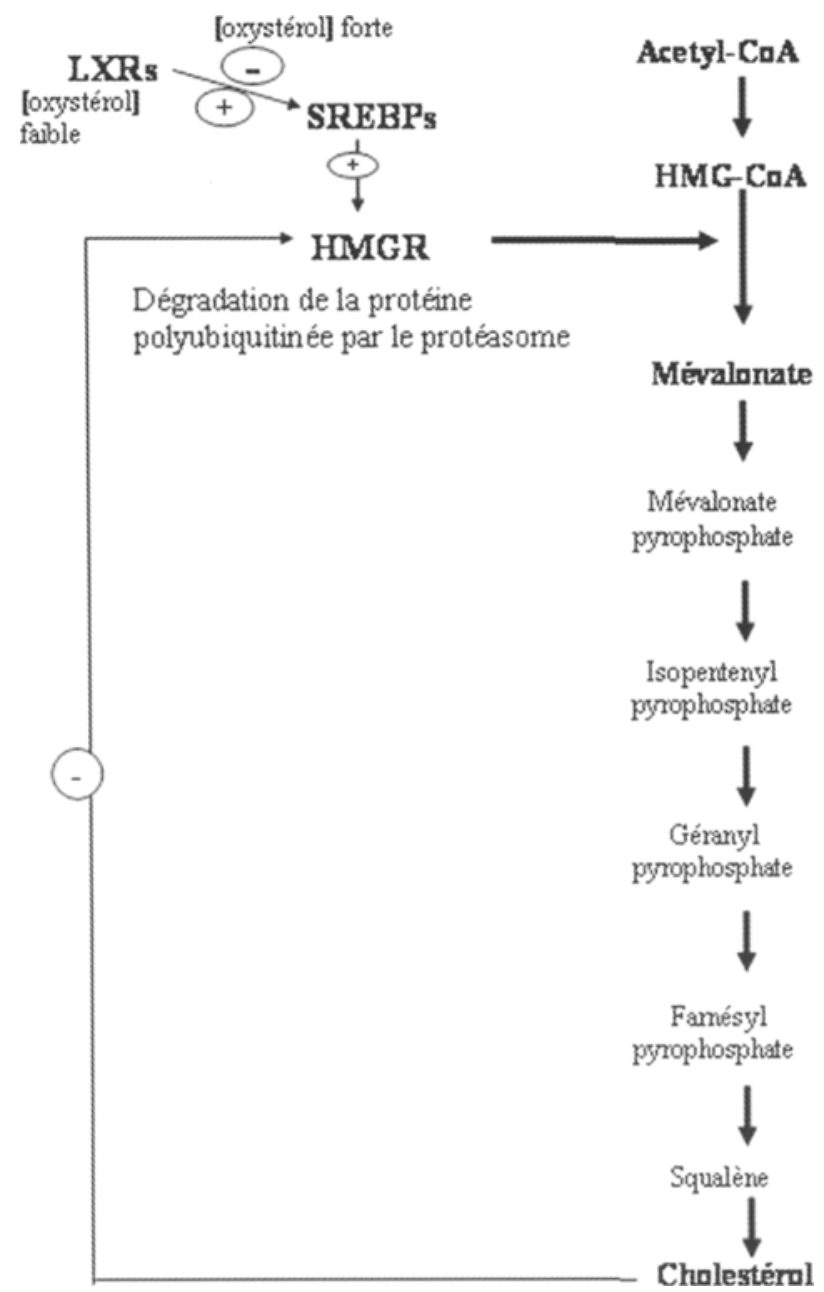

Figure 4 : Voie de synthèse du mévalonate qui aboutit à la synthèse du cholestérol. HMG-CoA : 3-hydroxy-3methylglutaryl-coenzyme-A; HMGR : 3-hydroxy-3methylglutaryl-coenzyme-A réductase ; CoA : coenzymeA ; LXRs : "Liver X Receptor "; SREBPs : "Sterol Regulatory Element Binding Proteins "; [oxystérols] : concentration en oxystérol ; + et - : régulation positive ou négative.

identifiées ne sont pas des cibles connues des LXRs, il faudra rechercher in silico la présence d'un LXRE dans le promoteur des gènes correspondant.

A plus long terme après avoir identifié un certain nombre de gènes régulés soit directement soit indirectement par LXRs au niveau de l'épididyme, il sera intéressant de mettre en relation cette régulation avec la maturation des spermatozoïdes et le maintien de la structure épithéliale de la tête de l'épididyme.

\section{REFERENCES}

1. ABE K., TAKANO H., ITO T. : Ultrastructure of the mouse epididymal duct with special reference to the regional differences of the principal cells. Arch. Histol. Jpn, 1983, $46: 51-68$.

2. ABOU-HAILA A., FAIN-MAUREL M.A. : Regional differences of the proximal part of mouse epididymis : morphological and histochemical characterization. Anat. Rec., 1984, 209 : 197208.

3. AKMAL K.M., DUFOUR J.M., KIM K.H. : Region-specific localization of retinoic acid receptor-alpha expression in the rat epididymis. Biol. Reprod., 1996, 54 : 1111-1119.

4. ANDERSEN O.M., YEUNG C.H., VORUM H. et al. : Essential role of the apolipoprotein $E$ receptor-2 in sperm development. J. Biol. Chem., 2003, $278:$ 23989-23995.

5. APFEL R., BENBROOK D., LERNHARDT E. et al. : A novel orphan receptor specific for a subset of thyroid hormoneresponsive elements and its interaction with the retinoid/thyroid hormone receptor subfamily. Mol. Cell Biol., 1994, 14 : 7025-7035.

6. BARONE R. : Anatomie Comparée des mammifères domestiques. Tome 4 Splanchnologie II. Paris, Vigot, 1990.

7. BRITAN A., LAREYRE J.J., LEFRANCOIS-MARTINEZ A.M. et al. : Spontaneously immortalized epithelial cells from mouse caput epididymidis. Mol. Cell Endocrinol., 2004, 224 : 41-53.

8. COHEN D.J., ROCHWEGER L., ELLERMAN D.A. et al. : Relationship between the association of rat epididymal protein "DE" with spermatozoa and the behavior and function of the protein. Mol. Reprod. Dev., 2000, 56 : 180-188.

9. COOPER T.G. : Role of the epididymis in mediating changes in the male gamete during maturation. Adv. Exp. Med. Biol., $1995,377: 87-101$.

10. CORNWALL G.A., CAMERON A., LINDBERG I. et al. : The cystatin-related epididymal spermatogenic protein inhibits the serine protease prohormone convertase 2. Endocrinology, 2003, 144 : 901-908.

11. CORNWALL G.A., HANN S.R. : Specialized gene expression in the epididymis. J. Androl., 1995, $16: 379-383$

12. CORNWALL G.A., LAREYRE J.J., MATUSIK R.J. et al. : Gene expression and epididymal function. In : Robaire B., Hinton B.T. eds. The epididymis : From molecules to clinical practice. New York, Kluwer Academic/Plenum Publishers, 2002 : 169-199.

13. CROSS N.L. : Role of cholesterol in sperm capacitation. Biol. Reprod., 1998, $59: 7-11$.

14. DACHEUX J.L., GATTI J.L., CASTELLA S. et al. : The epididymal protein. In : Hinton B.T., Turner T.T. eds. The third international conference on the epididymis. New York, The Van Doren Company, 2003, 115-122.

15. DACHEUX J.L., DACHEUX F. : Protein secretion in the epididymis. In : Robaire B., Hinton B.T. eds. The epididymis : From molecules to clinical practice. New York, Kluwer Academic / Plenum Publishers, 2002 : 151-168.

16. DREVET J.R., LAREYRE J.J., SCHWAAB V. et al. : The PEA3 protein of the Ets oncogene family is a putative transcriptional modulator of the mouse epididymis-specific glutathione peroxidase gene gpx5. Mol. Reprod. Dev.,1998, 49 : 131-140.

17. DUFAURE J.P., DREVET J.R. : La régulation de l'expression des gènes dans l'épididyme. Médecine/Science, 1998, 14 : $1392-1398$. 
18. EDDY E.M., WASHBURN T.F., BUNCH D.O. et al. : Targeted disruption of the estrogen receptor gene in male mice causes alteration of spermatogenesis and infertility. Endocrinology, 1996, $137: 4796-4805$.

19. FRENOUX J.M., VERNET P., VOLLE D.H. et al. : Nuclear oxysterol receptors, LXR, are involved in the maintenance of mouse caput epididymidis structure and sperm post-testicular maturational events. J. Mol. Endocrinol., 2004, 33 : 361-375.

20. FU X., MENKE J.G., CHEN Y. et al. : 27-hydroxycholesterol is an endogenous ligand for liver $X$ receptor in cholesterol-loaded cells. J. Biol. Chem., 2001, $276: 38378-38387$.

21. GARRETT J.E., GARRETT S.H., DOUGLASS J.A. : Spermatozoa-associated factor regulates proenkephalin gene expression in the rat epididymis. Mol. Endocrinol., 1990, $4: 108-118$.

22. GAUDREAULT C., LE GARE C., BERUBE B., SULLIVAN R. : Hamster sperm protein, p26h: a member of the short-chain dehydrogenase/reductase superfamily. Biol. Reprod., 1999, $61: 264-273$.

23. GLOVER T.D, NICANDER L. : Some aspects of structure and function in the mammalian epididymis. J. Reprod. Fertil., Suppl, 1971, $13: 39-50$.

24. HAIDL G., OPPER C. : Changes in lipids and membrane anisotropy in human spermatozoa during epididymal maturation. Hum. Reprod., 1997, 12 : 2720-2723.

25. HALL J.C., HADLEY J., DOMAN T. : Correlation between changes in rat sperm membrane lipids, protein, and the membrane physical state during epididymal maturation. J. Androl., 1991, $12: 76-87$.

26. HALL J.C., KILLIAN G.J.: Changes in rat sperm membrane glycosidase activities and carbohydrate and protein contents associated with epididymal transit. Biol. Reprod., 1987, 36 : 709-718.

27. HAMILTON D. : Anatomy of mamalian male accessory reproductive organs. In : Laming G. ed. Marshall's Physiology of Reproduction, reproduction in the Male. Edinburg, Churchill Livingston, 1990, Vol $2: 691-746$.

28. HAMPTON R.Y. : Proteolysis and sterol regulation. Ann. Rev. Cell Dev. Biol., 2002, $18: 345-378$.

29. HESS R.A., BUNICK D., LEE K.H. et al. : A role for oestrogens in the male reproductive system. Nature, 1997, 390 : 509-512.

30. HESS R.A., BUNICK D., LUBAHN D.B., ZHOU Q., BOUMA J. : Morphologic changes in efferent ductules and epididymis in estrogen receptor-alpha knockout mice. J. Androl., 2000, 21 : 107-121.

31. HINTON B.T., LAN Z.J., RUDOLPH D.B., LABUS J.C., LYE R.J. : Testicular regulation of epididymal gene expression. J. Reprod. Fertil., Suppl, 1998, $53:$ 47-57.

32. HUANG L.S., VOYIAZIAKIS E., CHEN H.L., RUBIN E.M., GORDON J.W. : A novel functional role for apolipoprotein $B$ in male infertility in heterozygous apolipoprotein $B$ knockout mice. Proc. Natl Acad. Sci. USA, 1996, 93 : 10903-10907.

33. JANOWSKI B.A., GROGAN M.J., JONES S.A. et al. : Structural requirements of ligands for the oxysterol liver $X$ receptors LXRalpha and LXRbeta. Proc. Natl Acad. Sci. USA, 1999, 96: 266-271.

34. KIRCHHOFF C. : Gene expression in the epididymis. Int. Rev. Cytol., 1999, $188:$ 133-202.

35. KIRSTEN M.R., GERTRUD U.S., KNUT R.S. et al. : The liver $X$ receptor is essential for maintaining cholesterol homeostasis in the testis. Endocrinology, 2005, $146: 2519-2530$.
36. LAN Z.J., LABUS J.C., HINTON B.T. : Regulation of gammaglutamyl transpeptidase catalytic activity and protein level in the initial segment of the rat epididymis by testicular factors : role of basic fibroblast growth factor. Biol. Reprod., 1998, 58 : 197-206.

37. LAREYRE J.J., CLAESSENS F., ROMBAUTS W., DUFAURE J.P., DREVET J.R. : Characterization of an androgen response element within the promoter of the epididymis-specific murine glutathione peroxidase 5 gene. Mol. Cell Endocrinol., 1997, $129:$ 33-46.

38. LAREYRE J.J., MATTEI M.G., KASPER S. et al. : Structure and putative function of a murine epididymal retinoic acid-binding protein (mE-RABP). J. Reprod. Fertil. Suppl, 1998, 53 : 59-65.

39. LEGARE C., BERUBE B., BOUE F. et al. : Hamster sperm antigen P26h is a phosphatidylinositol-anchored protein. Mol. Reprod. Dev., 1999, 52 : 225-233.

40. LEGARE C., GAUDREAULT C., ST-JACQUES S., SULLIVAN $\mathrm{R}$. : $\mathrm{P} 34 \mathrm{H}$ sperm protein is preferentially expressed by the human corpus epididymidis. Endocrinology, 1999, $140: 3318-$ 3327.

41. LOBACCARO J.M., REPA J.J., LU T.T. et al. : Regulation of lipid metabolism by the orphan nuclear receptors. Ann. Endocrinol. (Paris), 2001, $62:$ 239-247.

42. LU T.T., REPA J.J., MANGELSDORF D.J. : Orphan nuclear receptors as eLiXiRs and FiXeRs of sterol metabolism. J. Biol. Chem., 2001, $276:$ 37735-37738.

43. MERCIER-BODARD C., ALFSEN A., BAULIEU E.E. : Sex steroid binding plasma protein (SBP). Acta Endocrinol (Copenh), Suppl. 1970, $147:$ 204-224.

44. MOORE H.D., BEDFORD J.M. : The differential absorptive activity of epithelial cells of the rat epididymus before and after castration. Anat. Rec., 1979, 193 : 313-327.

45. MORTZ E., KROGH T.N., VORUM H., GÖRG A. : Improved silver staining protocols for high sensivity protein identification using matrix-assisted laser desorption/ionization time of flight analysis. Proteomics, 2001, $1: 1359-1363$.

46. NATH D., MAJUMDER G.C. : Maturation-dependent modification of the protein phosphorylation profile of isolated goat sperm plasma membrane. J. Reprod. Fertil., 1999, 115 : 2937.

47. PEET D.J., TURLEY S.D., MA W. et al. : Cholesterol and bile acid metabolism are impaired in mice lacking the nuclear oxysterol receptor LXR alpha. Cell, 1998, 93 : 693-704.

48. PERRY A.C., JONES R., HALL L. : Isolation and characterization of a rat cDNA clone encoding a secreted superoxide dismutase reveals the epididymis to be a major site of its expression. Biochem. J., 1993, $293:$ 21-25.

49. POLLANEN P., COOPER T.G. : Immunology of the testicular excurrent ducts. J. Reprod. Immunol., 1994, 26 :167-216.

50. RAVID T., DOOLMAN R., AVNER R., HARATS D., ROITELMAN J. : The ubiquitin-proteasome pathway mediates the regulated degradation of mammalian 3-hydroxy-3-methylglutaryl-coenzyme A reductase. J. Biol. Chem., 2000, 275 : 35840-35847.

51. REBECCA L.W., GORDON C., MAYER R.J. : Ubiquitin and ubiquitin-like proteins as multifunctional signals. Nature Reviews, 2005, 6 : 599-609.

52. REPA J.J., MANGELSDORF D.J. : The role of orphan nuclear receptors in the regulation of cholesterol homeostasis. Ann. Rev. Cell Biol., 2000, $16: 59-81$

53. ROBAIRE B., HERMO L. : Efferents ducts, epididymis, vas 
deferens : structure, functions, and their regulation. In : Knobil E. ed. The physiology of reproduction. New York, Raven Press, 1988 : 999-1080

54. ROBAIRE B., JERVIS K.M., EZER N. : Cell Dynamics and Death in the Epididymal Epithelium. In : Hinton B.T., Turner T.T. eds. The third international conference on the epididymis. New York, The Van Doren Company, 2003 : 35-49.

55. SHALGI R., SELIGMAN J., KOSOWER NS. : Dynamics of the thiol status of rat spermatozoa during maturation : analysis with the fluorescent labeling agent monobromobimane. Biol. Reprod., 1989, 40 : 1037-1045.

56. SINOWATZ F., VOLGMAYR J.K., GABIUS H.J., FRIESS A.E.: Cytochemical analysis of mammalian sperm membranes. Prog. Histochem. Cytochem., 1989, $19: 1-74$.

57. SORANZO L., DADOUNE J.P., FAIN-MAUREL M.A. : Segmentation of the epididymal duct in mouse : an ultrastructural study. Reprod. Nutr. Dev., 1982, 22 : 999-1012.

58. TEBOUL M., ENMARK E., LI Q., WIKSTROM A.C., PELTOHUIKKO M., GUSTAFSSON J.A. : OR-1, a member of the nuclear receptor superfamily that interacts with the 9-cis-retinoic acid receptor. Proc. Natl. Acad. Sci. USA, 1995, 92 : 2096-2100.

59. THUILLIER P., BAILLIE R., SHA X., CLARKE S.D. : Cytosolic and nuclear distribution of PPARgamma2 in differentiating 3T3-L1 preadipocytes. J. Lipid. Res., 1998, 39 : 2329-2338.

60. TRAMER F., ROCCO F., MICALI F., SANDRI G., PANFILI E. : Antioxidant systems in rat epididymal spermatozoa. Biol. Reprod., 1998, 59 : 753-758.

61. TULSIANI D.R., ORGEBIN-CRIST M.C., SKUDLAREK M.D. : Role of luminal fluid glycosyltransferases and glycosidases in the modification of rat sperm plasma membrane glycoproteins during epididymal maturation. J. Reprod. Fertil., Suppl., 1998, $53: 85-97$.

62. TULSIANI D.R., SKUDLAREK M.D., HOLLAND M.K. : Orgebin-Crist M.C. : Glycosylation of rat sperm plasma membrane during epididymal maturation. Biol. Reprod., 1993, 48 : 417428.

63. TURNER T.T., AVERY E.A., SAWCHUK T.J. : Assessment of protein synthesis and secretion by rat seminiferous and epididymal tubules in vivo. Int. J. Androl., 1994, $17:$ 205-213.

64. VERNET P., RIGAUDIERE N., GHYSELINCK N., DUFAURE J.P., DREVET J.R. : In vitro expression of a mouse tissue specific glutathione-peroxidase-like protein lacking the selenocysteine can protect stably transfected mammalian cells against oxidative damage. Biochem. Cell Biol., 1996, 74 : 125-131.

65. VISCONTI P.E., NING X., FORNES M.W. et al. : Cholesterol efflux-mediated signal transduction in mammalian sperm : cholesterol release signals an increase in protein tyrosine phosphorylation during mouse sperm capacitation. Dev. Biol., 1999, $214:$ 429-443.

66. VOLLE D.H., DÉCHELOTTE P., CUMMINS C.C. et al. : Deficient mice for oxysterol nuclear receptors LXRs show a rapid decrease of fertility associated with testicular destructuration. 2004 (en cours de préparation).

67. VOLLE D.H., FRENOUX J.M., MOUZAT K. et al. : Rôle des récepteurs nucléaires des oxystérols $L X R$ dans la régulation de l'homéostasie du cholestérol au niveau de l'appareil reproducteur mâle. Andrologie, 2005, $15: 151-159$.

68. WAN Y.J., WANG L., WU T.C. : Detection of retinoic acid receptor mRNA in rat tissues by reverse transcriptase-polymerase chain reaction. J. Mol. Endocrinol.,1992, $9: 291-294$.
Prix du meilleur DEA - SALF 2004

Manuscrit reçu : novembre 2005 ; accepté décembre 2005.

\section{ABSTRACT}

Screening for LXR target genes involved in the maintenance of mouse caput epididymis structure and function

Ayhan KOCER, Fabrice SAEZ, Kevin MOUZAT, Patrick VERNET, Jean-Marc A. LOBACCARO, Joël R. DREVET.

Liver $X$ receptors (LXRs) are involved in cholesterol homeostasis and lipid metabolism. Ixr knock-out mice for the two isoforms Ixra and Ixrb exhibit severe disruption of the structure of caput epididymidis segment 1 and 2 epithelium and increased sperm fragility. These defects generate infertility in 10-month-old male mice.

The role of LXRs in the epididymis have not yet been investigated. A cell line obtained from mouse caput epididymidis (B2 cells) was used to screen for LXR epididymal target genes in vitro. The presence of one isoform of LXR $(L X R \alpha)$ was detected by immunocytochemistry and the capacity of $B 2$ cells to respond to a synthetic agonist of LXRs (T0901317) was verified. These results validated the use of $\mathrm{B2}$ cells as a model. Bidimensional electrophoresis was performed on B2 cells treated with T0901317. Eight proteins up-regulated by LXRs were isolated. Only one protein has been identified: polyubiquitin, which has already been reported to be involved in cellular cholesterol homeostasis.

Key-words: epididymis, Nuclear receptors, LXR, cholesterol, male reproduction 